\title{
DISCALCULIA:
}

\section{UMA DIFICULDADE NA APRENDIZAGEM MATEMÁTICA EM BUSCA DE PRÁTICAS DE PESQUISAÇÃO EM SALA DE AULA}

1 Sueli Karanauskas

2 Dulcilene R. S. Nascimento

\section{RESUMO}

Constatam-se, atualmente, inúmeras dificuldades dos alunos, relacionadas à capacidade de resolver problemas matemáticos e certas habilidades em cálculos. Assim, a presente pesquisa irá mostrar que o termo discalculia é usado frequentemente ao referir-se, especificamente, a inabilidade de executar operações matemáticas ou aritméticas. É, pois, um distúrbio neuropsicológico caracterizado pela dificuldade no processo de aprendizagem do cálculo, e que se observa, geralmente, em indivíduos de inteligência normal que apresentam inabilidades para a realizações das operações matemáticas e falhas no raciocínio lógico-matemático. Para a realização da pesquisa optou-se por uma abordagem teórica, bibliográfica, com enfoque qualitativo dos dados e informações relevantes quanto ao processo de ensino.

Palavras-chave: Discalculia; Dificuldade de aprendizagem; Ensino de Matemática. 


\section{ABSTRACT}

Currently, there are numerous difficulties of students, related to the ability to solve mathematical problems and certain skills in calculations. Thus, the present scientific research will show that the term dyscalculia is often used when referring specifically to the inability to perform mathematical or arithmetic operations. It is, therefore, a neuropsychological disorder characterized by difficulty in the learning process of calculus, and which is generally observed in individuals of normal intelligence who have disabilities to perform mathematical operations and failures in logicalmathematical reasoning. To carry out the research, we opted for a theoretical, bibliographic approach, with a qualitative focus of the relevant data and information regarding the teaching process.

Keywords: Dyscalculia; Learning difficulties; Mathematics teaching.

1 Sueli Karanauskas é Doutoranda em Educação pela Unilogos-EUA, Mestre pela Universidade São Marcos em Educação, Administração e Comunicação. Atualmente é diretora da Faculdade da Interativa de São Paulo, Professora e pesquisadora na aréa de Metodologias Ativas voltada ao ensino à distância e de estudos voltados a área de inclusão no Brasil.

2 Dulcilene R.S Nascimento Nascimento é PHD e Doutora em História, Mestre em Ciência Política, Cidadania e Governação, Mestre em Educação, Especialista em Metodologia do Ensino, Pesquisa com extensão em Educação e Licenciada em História.

\section{INTRODUÇÃO}

O foco desta pesquisa é a discalculia, em cujo estudo o pesquisador busca formas de compreendê-la para intervir pedagogicamente no sentido de superar esse déficit de aprendizado e entendendo que esta temática apesar de corriqueira ainda constitui um desafio para o professor em sala de aula e para os especialistas, o que denota a sua necessidade enquanto prática de pesquisa em educação. 
A escolha desse tema foi uma necessidade de saber mais sobre o assunto, já que trabalho com educação infantil. Então me veio o questionamento do que eu poderia fazer para desenvolver um trabalho mais minucioso e me aprofundar mais sobre o tema.

Estudos apontam que a discalculia pode se causada por vários elementos que abrangem áreas de estudo como a neurologia, a linguística, a psicológica, a genética e a pedagógica.

O termo discalculia é usado frequentemente ao referir-se, especificamente, a inabilidade de executar operações matemáticas ou aritméticas. É pois, um distúrbio neuropsicológico caracterizado pela dificuldade no processo de aprendizagem do cálculo, e que se observa, geralmente, em indivíduos de inteligência normal que apresentam inabilidades para a realizações das operações matemáticas e falhas no raciocínio lógico-matemático.

De acordo com vários autores, crianças portadoras de discalculia, são incapazes de identificar sinais matemáticos, montar operações, classificar números, entender princípios de medidas, seguir sequências, compreender conceitos matemáticos, relacionar o valor de moedas entre outros.

Para tanto, cientistas procuram ainda compreender as causas da discalculia, investigando em diversos domínios: Neurológico, déficits na memória trabalhando, desordem congênita ou hereditária e várias combinações destes fatores.

Cada vez mais, o número de pessoas, sejam adultos ou crianças com sintomas discalcúlicos aumenta significantemente. Faremos um convite para a reflexão a respeito dos aspectos que causam esse distúrbio, seja ele de qualquer domínio.

A integração envolve inúmeros aspectos. A integração em si é um valor absolutamente transmissível, que diz respeito a participação de todos para que se alcance um objetivo.

É preciso que, toda sociedade se mobilize, procurando recursos e possibilidades de uma solução, e, que família e escola trabalhem juntas para se obter um resultado positivo. Não devendo ser só um objetivo dos profissionais de saúde, más sim um dever de todos os seguimentos da sociedade, por meio de um esforço contínuo para garantir que seja o principal objetivo de uma educação que se pretende: Democrática e principalmente humana.

Muito se discute sobre as condições necessárias de estudos mais amplos e definidos sobre as causas e sintomas desse distúrbio. 
Sem dúvida, é necessário que essas questões sejam contempladas com pesquisas e recursos modernos para busca de soluções e condições mais específicas desse mal quase desconhecido.

Por tudo isso, precisamos entender que é um distúrbio que atinge crianças desde a pré-escola até adultos no final do seu ciclo de vida.

\section{CONCEITUANDO A DISCALCULIA}

A educação moderna volta-se cada vez mais para encerrar o ciclo do ensino por adestramento, pela aprendizagem consciente, onde o aluno é estimulado continuamente a aprimorar a sua capacidade de pensar.

A importância de um estudo, mais específico sobre um tema discalculia, deve ser de grande valia para o desenvolvimento humano.

Teresinha Caraher, em sua obra apresenta valiosa contribuição enquanto advertência para que o educador não subestime as formas espontâneas de raciocínio, cálculos mentais e maneiras inventadas para resolver e operar problemas com as descobertas que a criança trás para a escola, e que devem ser incorporadas a metodologia utilizada para o trabalho com matemática.

Tudo demonstrado neste texto a partir da análise de uma pesquisa relevante vem nos mostrar, que apesar do número pequeno de estudos sobre o tema, cada vez mais pessoas se interessam em pesquisar e procurar ajuda para os portadores de discalculia.

Segundo J.N.Garcia (1998), dificuldades de aprendizagem (DA) é um termo geral que se refere ao um grupo heterogêneo de transtornos que se manifestam por dificuldades significativas na aquisição do uso da escuta, fala, leitura, raciocínio ou habilidades matemáticas.

O medo apresenta uma das emoções normais da vida do ser humano. É um estado emocional de alerta, que se caracteriza por sensação de desconforto e ansiedade diante do perigo. (Jose e Coelho, 2002, p. 176.)

Para que o professor consiga detectar a discalculia em um aluno, é imprescindível que ele esteja atento a trajetória da aprendizagem desse aluno, principalmente quando ele apresentar símbolos matemáticos malformados, demonstrar incapacidade de operar com quantidades numéricas, não reconhecer os 
sinais das operações, apresentar dificuldades na leitura de números e não conseguir localizar espacialmente a multiplicação e a divisão. Caso o transtorno não seja conhecido a tempo, pode comprometer o desenvolvimento escolar da criança, que com medo de enfrentar novas experiências de aprendizagem adota comportamentos inadequados, tornando-se apática, agressiva ou desinteressada.

O aluno em perfeitas condições neurológicas é capaz de desenvolver todas as suas habilidades e competências, o que não acorre com aquele que apresenta as características da discalculia, que consiste numa desordem que afeta a habilidade de lidar com os números.

Cabe ressaltar que pessoas disléxicas com frequência, são bem-dotadas em matemáticas. Elas têm habilidades em três dimensões, que as ajudam a assimilar conceitos mais clara e rapidamente que pessoas não disléxicas.

No entanto, a discalculia, como dislexia possui aspectos relevantes que a caracteriza, por exemplo, pela falta de memória temporária, deficiência na leitura e escrita e a inversão de caracteres ligados aos símbolos da matemática.

Assim, os portadores de discalculia tem dificuldades em ler e escrever, interpretar os grafemas usados como indicadores de significados para representar a necessidade de operações. Os sujeitos não decodificam os símbolos e, portanto, não operam, ou não realizam atividades com eles.

"Não se alfabetizar depois de certo tempo é facilmente notável. Más não saber matemática é algo, digamos, comum, dentro da escola. Por isso, muitas vezes, a discalculia acaba passando despercebida". (Sylwe Maschitto)

As dificuldades da matemática devem ser vistas de formas diferentes, dependendo da idade, do desenvolvimento nas habilidades de matemática. Durante a infância e a adolescência a bagagem psicológica que regerá o adulto não está consolidada entre as construções psicológicas, mas afetadas com o passar dos anos.

Quando as dificuldades apresentadas na matemática são apenas de natureza procedimental devemos nos perguntar se a dificuldade decorreria de um aprendizado insuficiente da matemática e não necessariamente de um transtorno de aprendizagem.

Ainda assim, a melhor forma de obter essa resposta é por meio de um olhar interdisciplinar. 


\section{O QUE A ESCOLA PODE FAZER}

Pode-se perceber que o tratamento da discalculia é composto por profissionais tanto na área educacional e de profissionais da área da saúde. Assim, é notória a gravidade e a importância de se conhecer e saber lidar com a discalculia que é cada vez mais presente e cada vez menos difundida.

Para efetivar a aprendizagem, objetivo primeiro da escola, as atividades escolares devem ser produtos da reflexão do coletivo da escola, pois o planejamento dessas atividades é indispensável para que a escola consiga desempenhar bem o seu papel. Pois, "isoladamente, ainda que haja competência e comprometimento, os resultados do trabalho educacional são quase sempre insignificantes." (FONSECA, 1995). A partir dessa reflexão, surgirão os caminhos a serem seguidos na ação educacional, concretizados na forma de proposta pedagógica, planos de curso e no plano de gestão escolar.

O projeto político pedagógico da escola será o referencial para que essas distorções sejam corrigidas. A melhor, para não dizer a única, forma de ter sucesso na educação moral, na formação ética e na pacificação das relações é, no seio da escola, trabalhar a qualidade do convívio social entre seus membros (professores, alunos, funcionários e pais). Logo, em vez de limitar-se a impor inúmeras regras, é melhor a escola deixar claro, para todos, os princípios que inspiram a convivência social. A elaboração de regras - que pode ser feita pela comunidade como um todo - será derivada da apreciação desses princípios. E esses princípios devem estar contidos no PPP da escola.

É na elaboração de um projeto comum que se encontra a possibilidade de participação dos diferentes atores do processo pedagógico nos destinos da escola.

\section{O QUE O PROFESSOR PODE FAZER}

Para ajudar seus alunos o professor poderá explicá-los sobre suas dificuldades e tentar ajuda-lo sempre que precisar, procurando utilizar situações - problemas que 
envolvam o cotidiano do aluno, para que o conteúdo faça sentido para o indivíduo e que este se sinta motivado ao trabalhar com a disciplina.

O papel do professor no processo de aprendizagem é indiscutivelmente decisivo, suas atitudes, concepções e intervenções, serão fatores determinantes no sucesso ou fracasso escolar de seus alunos. Já o educando quando chega à escola traz consigo muitas experiências que não devem ser ignoradas pelo professor, pois mesmo antes de ingressar na escola a criança já possui inúmeras vivências que podem servir como ponto de partida para uma aprendizagem significativa.

Tanto professor quanto escola devem aliar-se a essa tríade: experiências vividas, conhecimentos prévios e materiais diversos, resultando na aprendizagem significativa. A escola, enquanto espaço de promoção do saber tem a função de proporcionar momentos de dúvidas e descobertas. Já o educador, enquanto mediador da aprendizagem tem, como uma de suas funções, investigar a dúvida, provocar o educando para a indagação do que anseia aprender e mostrar-Ihe que há várias fontes de saber. (TAVARES, 1996, p.44).

Também neste contexto é importante dizer que o professor ajude os alunos a estabelecer relações entre o que já aprenderam e o que estão aprendendo, criando em sala de aula um ambiente favorável à troca de ideias.

Isso significa que os professores devem constantemente propor questões que possibilitem aos alunos refletir sobre o que sabem e o que estão aprendendo. $O$ professor deve sempre despertar o interesse do aluno pela matemática. Essa tarefa é mais difícil para o aluno portador da discalculia, mas o professor é aquele que vai sensibilizá-lo para a ação.

Os neurocientistas, psicólogos e fonoaudiólogos enfatizam que a discalculia não tem cura, mas existe tratamento e didáticas metodológicas ajustáveis que possibilitam o desenvolvimento desses indivíduos tranquilamente. O tratamento para o indivíduo com discálculico deve acompanhar o mesmo caminho. Assim como pessoas portadoras de dislexia têm uma mente brilhante e totalmente acessível para desenvolver habilidades próprias, utilizando áreas específicas do seu hemisfério cerebral; as pessoas com discalculia também possuem capacidade de surpreender seus pais e professores, devido à capacidade intelectual para adquirir conhecimento 
específico com a ajuda e intervenção de professores especializados e encaminhamento adequado.

É importante lembrar que a discalculia pode causar profundos efeitos negativos na personalidade se não for acompanhada adequadamente, mas também poderá ter numerosos efeitos positivos tanto na personalidade quanto na vida escolar e profissional da pessoa quando tiver a atenção correta e eficiente da escola e da família.

Levando em conta a dificuldade de identificar o aluno portador de discalculia, é importante que o professor possa o mais rápido possível, identificar de forma segura, o distúrbio de aprendizagem do aluno, e encaminhá-lo. É importante a escola contar com uma equipe multidisciplinar para os diagnósticos e fazer as intervenções necessárias e os encaminhamentos específicos.

É notável a insegurança dos profissionais da educação ao relatar acrescente presença em sala, de alunos que apresentam dificuldades de aprendizagem na linguagem escrita como: discalculia, disgrafia, dislexia entre outros. Somada a isso o despreparo e ou negligência da família agrava mais os casos.

A compreensão da família frente às dificuldades encontradas pelo individuo é de extrema importância, uma vez que é nesse ambiente que ele vai buscar conforto para seus possíveis problemas. Procurar observar e estar ao lado acompanhando os processos que a criança passa até chegar ao seu desenvolvimento pleno é um dever da família, principalmente se esta se encontra com dificuldades em qualquer âmbito, necessitando de maiores auxílio e atenção.

Deixar a criança se sentir segura no ambiente em que vive notando o carinho e dedicação da família auxilia no trabalho com alunos com esse tipo de transtorno e até atenua possíveis problemas que se desencadeiam por conta desses problemas como baixa auto estima, depressão e rejeição por parte de colegar e pessoas do convívio em geral.

Na realidade, faz-se necessária a investigação do desenvolvimento psicofísico social do paciente e dos antecedentes familiares, com interesse nos fatores genéticos relativos aos transtornos de aprendizagem através de avaliações por especialistas das diversas áreas. 
Os prejuízos dos indivíduos que apresentam discalculia são muito graves. A falta de acompanhamento e atendimento rápido e adequado tem excluído inúmeros alunos das escolas, levando-os a desistir, pois eles apresentam acentuada baixa autoestima e desesperança, já que são estigmatizados por não aprender com facilidade, ou em consequência da falta de aprendizagem considerada normal tornarem-se com comportamento difícil e assim serem taxados como perturbadores, hiperativos, incapazes, improdutivos, lentos, desorientados ou que estão "no mundo da lua". Isolando-se na dificuldade e timidez. Sendo assim desmotivados, abandonam a escola, interrompendo projetos e sonhos.

Por último, é preciso sublinhar que é necessário a continuação dessas pesquisas, a exploração minuciosa desse problema, para que mais pessoas tomem conhecimento e possam ajudar seus alunos e até mesmo sua família. É preciso que o professor seja instrumentalizado para fazer de sua sala de aula um local de pesquisa e intervenção para esses casos.

A questão que se coloca é como essa pesquisa deve ser feita e apresentada de forma mais acessível, ou seja, perpassa pela formação do professor e sua observação da realidade que o circunda.

\section{CONSIDERAÇÕES FINAIS}

Devido à complexidade dos distúrbios de aprendizagem os resultados para sua solução serão mais concretos se houver participação conjunta da família e da escola. Cada criança precisa ser vista de forma particular pois é em casa que a criança recebe as primeiras e mais duradouras influências que servem de base para as futuras aprendizagens, cabendo à escola o papel de complementar e dirigir a formação integral da criança.

É um grande desafio identificar, diagnosticar e fazer as intervenções necessárias para que a aprendizagem do aluno seja satisfatória, para sua vida acadêmica e para sua autoestima. È necessário atenção para não rotular, condenando um aluno para o resto de sua vida.

As dificuldades de aprendizagem ainda são assunto pouco explorado nas escolas. O diagnóstico equivocado leva a encaminhamentos para tratamentos 
desnecessários e à exclusão, tirando a oportunidade do aluno de superar suas dificuldades.

É preciso levar o tema para dentro da escola - não como assunto pontual, mas uma discussão permanente - contemplando as diversas dimensões da vida do aluno, como mais um instrumento para seu desenvolvimento integral, visto que as dificuldades de aprendizagem não têm como causa apenas um fator.

Conclui-se que as dificuldades em aprendizado de matemática podem ser denominadas como distúrbio e neste com o nome de discalculia.

Deve-se assim proporcionar a criança, pais, educadores e interessados em geral, a informação sobre este distúrbio específico, muitas vezes por falta de informação, acaba-se agindo de forma errada, jogando esta dificuldade nas próprias crianças.

Nesta pesquisa observou-se também que poucos são os estudos específicos sobre discalculia, o que motiva o pesquisador a destacar a necessidade de pesquisas mais aprofundadas sobre o assunto, o que por certo, trará grandes benefícios aos professores interessados e aos alunos pelos resultados que terá em seu aprendizado.

Portanto, a partir da análise das pesquisas pôde-se observar que houve muita dificuldade em conseguir material desse respaldo por existirem poucas pesquisas que tratam especificamente da discalculia, sobretudo no Brasil. 


\section{REFERÊNCIAS}

ALMEIDA, Cínthia Soares de; GONTIJO, Cleyton Hércules. Dificuldades de aprendizagem em matemática e a percepção dos professores em relação a fatores associados ao Insucesso nesta área. Disponível em: http://www.desenho.ufpr.br/IIISIPEM/GT7 B.pdf . Acesso em 12 dez. 2019.

BRASIL (1998). Ministério de Educação. Secretaria de Educação Básica.

Parâmetros curriculares nacionais: Matemática. Disponível em: http://portal.mec.gov.br/seb/arquivos/pdf/matematica.pdf . Acesso em: 15 nov.2019.

CARRAHER, Teresinha Nunes (org.) Aprender Pensando. Petrópolis, Vozes, 2002.

DIAS, Fernanda. O sintoma na aprendizagem da matemática. Disponível em:

<http://www1.fapa.com.br/monographia/artigos/3edicao/FERNA NDADIAS.pdf>.

Acesso em: 12 dez 2007.

FONSECA, Vitor da. Introdução às dificuldades de aprendizagem . 2ª ed., Porto Alegre: Artes Médicas, 1995.

GARCIA, J.N. Manual de Dificuldades de aprendizagem. Porto Alegre, Artmed, 1998.

JOSÉ, Elisabete da Assunção, Coelho. Problemas de aprendizado. São Paulo, Ática, 2002.

LOPES, Aurea. Será que seu aluno é disléxico? Revista Nova Escola a.xx, n.188, p. 60-62, dez 2005. 
MARTINS Vicente. Como Descobrir Uma Criança Disléxica BELLO, José Luiz de Paiva. Pedagogia em Foco. Fortaleza, $2001 . \quad$ Disponível em: www.pedagogiaemfoco.pro.br/spdslx01.htm . Acessado em: 10/06/2019.

MOURA, M. O. A séria busca no jogo. do lúdico na matemática. In KISHIMOTO, T.

(Org.). Jogo, brinquedo, brincadeira e a educação. 2 ed. São Paulo, Cortez, 1996.

p. 73-87.

PASQUALE, Silvana Fonseca Del Ponte. O lúdico como recurso psicopedagógico no processo de ensino e aprendizagem da matemática com crianças que apresentam discalculia na $2^{2}$. série. Monografia (Especialização em Psicopedagogia Universidade Guarulhos, UnG. Guarulhos/SP, 2004.

RISÉRIO, Taya Soledad. Definição dos transtornos de aprendizagem. Programa de (re) habilitação cognitiva e novas tecnologias da inteligência. 2003.

REIS, Silvia Marina Guedes dos. A Matemática no cotidiano Infantil: Jogos e atividades com crianças de 3 a 6 anos para o desenvolvimento do raciocínio lógico matemático. Campinas/SP: Papirus, 2006.

TAVARES, C. F. Curiosidade: uma aliada na aprendizagem. Revista do Professor. Rio Pardo: CPOEC. № 45. p. 31-32, janeiro/março, 1996. 